\title{
Carta resposta referente ao artigo "Alterações radiográficas femoropatelares na insuficiência do ligamento cruzado anterior”. Rev Bras Ortop 2015;50(1):43-49
}

\author{
Response Letter Regarding the Article "Femoropatellar \\ Radiographic Alterations in Cases of Anterior Cruciate \\ Ligament Failure”. Rev Bras Ortop 2015;50(1):43-49
}

\author{
Diego Protásio de Vasconcelos ${ }^{1}$ Alan de Paula Mozella ${ }^{1}$ Hugo Alexandre de Araújo Barros Cobra ${ }^{1}$ \\ Pedro Guilme Teixeira de Sousa Filho ${ }^{1}$ Gustavo Cardilo Oliveira ${ }^{1}$
}

${ }^{1}$ Serviço de Ortopedia e Traumatologia, Hospital Universitário,
Universidade Federal de Sergipe, Aracaju, SE, Brasil

Rev Bras Ortop 2020;55(4):505-506.

Endereço para correspondência Diego Protásio de Vasconcelos, MD, Av Gonçalo R. Leite 1660/903, Suíssa, Aracaju, SE, 49050-370, Brasil (e-mail: diegoprotasio@yahoo.com.br).

A insuficiência do ligamento cruzado anterior (LCA) causa alterações biomecânicas e cinemáticas na articulação tibiofemoral, ${ }^{1,2}$ podendo secundariamente causar alterações femoropatelares. ${ }^{3}$ Em nosso estudo, analisamos o comportamento de três parâmetros radiográficos femoropatelares (altura patelar pelo método de Caton-Deschamps, ângulo de congruência patelar de Merchant, e ângulo de inclinação lateral da patela de Laurin) em joelhos com insuficiência crônica isolada do LCA há > 12 meses, comparando-os com joelhos contralaterais normais.

Em relação aos critérios de inclusão da amostra, reforçamos que apenas foram selecionados pacientes com lesão crônica isolada do LCA em um dos joelhos (grupo caso, $n=30$ ) e joelho contralateral normal (grupo controle, $n=30$ ). Concordamos que a presença de lesão prévia do ligamento patelofemoral medial (LPFM), ou episódio prévio de luxação lateral da patela, poderiam alterar os índices radiográficos estudados. Desta forma, conforme destacado na Tabela 1 do nosso artigo original, ${ }^{4}$ enfatizamos que a presença de quaisquer lesões ou alterações prévias de qualquer origem, inclusive traumática, em qualquer um dos joelhos, à exceção da lesão isolada do LCA em um dos joelhos, seria critério de exclusão. Para isto, realizamos história clínica e exame físico dos membros inferiores em busca de quaisquer alterações, além dos sinais de insuficiência isolada unilateral do LCA. Imagem de ressonância

recebido

15 de Julho de 2019

aceito

23 de Julho de 2019
DOI https://doi.org/ 10.1055/s-0039-1700825. ISSN 0102-3616. magnética (IRM) também foi analisada para afastar lesões associadas. Desta forma, pacientes com história prévia de luxação lateral de patela ou sinais de lesão do LPFM foram excluídos.

As radiografias digitais obtidas foram analisadas pelo mesmo avaliador, que não conhecia os propósitos das medições ou grupos de estudo. A avaliação por um único avaliador "cego" foi escolhida devido à grande quantidade de medições necessárias ao estudo (240 medições em 60 joelhos) e ao perfil assistencial de alta demanda da nossa instituição. Porém, concordamos que a mensuração por mais de um avaliador seria a ideal e o cálculo dos coeficientes de correlação inter- e intraobservador agregaria valor estatístico, sendo uma limitação do nosso trabalho.

A análise estatística comparativa dos valores dos parâmetros estudados nos dois grupos foi realizada utilizando o teste t de Student, o qual se aplica para comparar valores que apresentam distribuição normal, onde valores médios (média) e mediana são muito próximos. Foram aplicados, para todos os grupos de valores obtidos, dois testes de normalidade (Kolmogorov-Smirnov e Shapiro-Wilk), e ambos determinaram distribuição normal da amostra, com valores de média e mediana muito próximos. Ao avaliar os valores de inclinação lateral da patela no grupo caso $(n=30)$, encontramos em apenas dois joelhos uma inversão do ângulo
Copyright $\odot 2020$ by Sociedade Brasileira License terms de Ortopedia e Traumatologia. Published by Thieme Revinter Publicações Ltda, Rio de Janeiro, Brazil 
de Laurin $\left(-2,2^{\circ} \mathrm{e}-4,8^{\circ}\right)$. Concordamos que valores outliers poderiam prejudicar a avaliação do teste $\mathrm{t}$ de Student, mas isto somente aconteceria se estes valores provocassem uma distorção entre média e mediana na amostra estudada. Em nossa análise estatística, observamos que a inclusão desses valores $\left(-2,2^{\circ} \mathrm{e}-4,8^{\circ}\right)$ não provocou distorção entre média e mediana no grupo de valores, ou seja, não alterou a distribuição normal da amostra, o que validaria o uso do teste t de Student.

\section{Conflitos de Interesses}

Os autores não têm conflitos de interesses a declarar

\section{Referências}

1 Li G, Park SE, DeFrate LE, et al. The cartilage thickness distribution in the tibiofemoral joint and its correlation with cartilage-to-cartilage contact. Clin Biomech (Bristol, Avon) 2005;20(07):736-744

2 Van de Velde SK, DeFrate LE, Gill TJ, Moses JM, Papannagari R, Li G. The effect of anterior cruciate ligament deficiency on the in vivo elongation of the medial and lateral collateral ligaments. Am J Sports Med 2007;35(02):294-300

3 Baugher WH, Warren RF, Marshall JL, Joseph A. Quadriceps atrophy in the anterior cruciate insufficient knee. Am J Sports Med 1984;12(03):192-195

4 Vasconcelos DP, Mozella AP, Sousa Filho PG, Oliveira GC, Cobra HA. Alterações radiográficas femoropatelares na insuficiência do ligamento cruzado anterior. Rev Bras Ortop 2015;50(01):43-49 